\title{
Similar long-term survival of consecutive in-hospital and out-of-hospital cardiac arrest patients treated with targeted temperature management
}

This article was published in the following Dove Press journal:

Clinical Epidemiology

9 November 2016

Number of times this article has been viewed

\author{
Magaly Engsig' \\ Helle Søholm² \\ Fredrik Folke ${ }^{3,4}$ \\ Peter J Gadegaard' \\ Julie Therese Wiis ${ }^{5}$ \\ Rune Molin ${ }^{6}$ \\ Thomas Mohrl \\ Frederik N Engsig ${ }^{7}$ \\ 'Department of Anaesthesiology \\ and Intensive Care, Copenhagen \\ University Hospital, Hellerup, \\ ${ }^{2}$ Department of Cardiology, \\ Copenhagen University Hospital, \\ Herlev, ${ }^{3}$ Department of Cardiology, \\ Copenhagen University Hospital, \\ Hellerup, ${ }^{4}$ Pre-Hospital Emergency \\ Medical Services, Capital Region of \\ Denmark, Ballerup, ${ }^{5}$ Department \\ of Intensive Care, Copenhagen \\ University Hospital, Copenhagen, \\ ${ }^{6}$ Department of Anaesthesiology, \\ Copenhagen University Hospital, \\ Hillerød, ${ }^{7}$ Department of Infectious \\ Diseases, Copenhagen University \\ Hospital, Hvidovre, Denmark
}

Objective: The long-term survival of in-hospital cardiac arrest (IHCA) patients treated with targeted temperature management (TTM) is poorly described. The aim of this study was to compare the outcomes of consecutive IHCA with out-of-hospital cardiac arrest (OHCA) patients treated with TTM.

Design, setting, and patients: Retrospectively collected data on all consecutive adult patients treated with TTM at a university tertiary heart center between 2005 and 2011 were analyzed.

Measurements: Primary endpoints were survival to hospital discharge and long-term survival. Secondary endpoint was neurological outcome assessed using the Pittsburgh cerebral performance category (CPC).

Results: A total of 282 patients were included in this study; 233 (83\%) OHCA and 49 (17\%) IHCA. The IHCA group presented more often with asystole, received bystander cardiopulmonary resuscitation (CPR) in all cases, and had shorter time to return of spontaneous circulation (ROSC). Survival to hospital discharge was 54\% for OHCA and 53\% for IHCA (adjusted odds ratio 0.98 [95\% confidence interval $\{\mathrm{CI}\} ; 0.43-2.24]$ ). Age $\leq 60$ years, bystander CPR, time to ROSC $\leq 10 \mathrm{~min}$, and shockable rhythm at presentation were associated with survival to hospital discharge. Good neurologic outcome among survivors was achieved by $86 \%$ of OHCA and $92 \%$ of IHCA ( $P=0.83$ ). After a median follow-up time of $>5$ years, $83 \%$ of OHCA and $77 \%$ of IHCA were alive (adjusted hazard ratio [HR] 1.51 [95\% CI; 0.59-3.91]). Age $\leq 60$ years was the only factor associated with long-term survival (adjusted HR 2.73 [95\% CI; 1.36-5.52]).

Conclusion: There was no difference in short- and long-term survival and no difference in neurologic outcome to hospital discharge between IHCA and OHCA patients treated with TTM despite higher frequency of asystole in IHCA.

Keywords: retrospective observational study, in-hospital survival, neurological outcome, advanced life support, post-resuscitation care

\section{Introduction}

In the past decade, the survival after out-of-hospital cardiac arrest (OHCA) has increased from a few percent to $\sim 10 \%$ in many countries. ${ }^{1}$ The increased survival has been attributed to improvements in all four links in the "chain-of-survival" guidelines with a large increase in bystander cardiopulmonary resuscitation (CPR), improved prehospital care, improved advanced life support guidelines, and focus on postresuscitation care. ${ }^{2}$ The use of targeted temperature management (TTM) is believed to reduce global ischemia and reperfusion injury processes present in all cardiac arrest patients. ${ }^{3}$ In 2002, two randomized controlled trials showed that treatment with TTM
Correspondence: Magaly Engsig Department of Anaesthesiology and Intensive Care, Copenhagen University Hospital, Kildegårdsvej 28, Gentofte, 2900 Hellerup, Denmark

Tel +4523965 592

Fax +4538677625

Email Magaly.Engsig@regionh.dk 
with a target temperature of $32^{\circ} \mathrm{C}-34^{\circ} \mathrm{C}$ during $12-24 \mathrm{~h}$ for comatose patients after cardiac arrest improved survival and neurological outcome; however, these trials included only patients after OHCA and mostly with ventricular fibrillation (VF). ${ }^{4,5} \mathrm{~A}$ more recent controlled, randomized study that included only OHCA patients with both shockable and non-shockable initial rhythm showed no difference in the outcomes of patients treated with $33^{\circ} \mathrm{C}$ compared to $36^{\circ} \mathrm{C} .{ }^{6}$ Consequently, recently updated international guidelines now recommend a target temperature between $32^{\circ} \mathrm{C}$ and $36^{\circ} \mathrm{C}$ for $24 \mathrm{~h}$ after OHCA and they still strongly recommend the same therapy for patients with non-VF OHCA or in-hospital cardiac arrest (IHCA) patients as well. ${ }^{7}$ Nevertheless, the only existing evidence that supports this practice comes from cohort studies that have shown variable results. ${ }^{8-11}$ Furthermore, results from the few existing studies on the IHCA population treated with TTM usually do not include survival beyond hospital discharge. The aim of this study was to compare survival to discharge, long-term survival, and neurologic outcome between consecutive OHCA and IHCA patients treated with TTM.

\section{Materials and methods Study population and setting}

This retrospective observational study included all consecutive adult patients admitted to the intensive care unit (ICU) in a single tertiary heart center (Copenhagen University Hospital, Gentofte, Denmark) treated with TTM after OHCA or IHCA from April 1, 2005 to March 31, 2011. Patients with cardiac arrest as the diagnosis on admission and TTM as procedure code were identified from the ICU critical information system database, and all data were obtained by reviewing the medical records.

At the institution, a TTM protocol was implemented in 2004 based on international recommendations for patients who remained comatose after cardiac arrest. ${ }^{12}$ According to the local TTM protocol, indications for TTM were: age $\geq 18$ years, suffered cardiac arrest (OHCA or IHCA), Glasgow Coma Scale $\leq 8$ on arrival at the hospital (or the ICU for IHCA), and $<60 \mathrm{~min}$ from collapse to return of spontaneous circulation (ROSC). Contraindications for TTM were: terminal illness before the arrest, core temperature $<30^{\circ} \mathrm{C}$, pregnancy, intracranial hemorrhage, arterial oxygen saturation $<85 \%$ for $>15 \mathrm{~min}$ after ROSC, and refractory cardiogenic shock (median arterial pressure $<60 \mathrm{mmHg}$ for $>30 \mathrm{~min}$ after ROSC despite the use of vasoactive drugs or intra-aortic balloon pump [IABP]).

\section{Post-resuscitation care}

Patients presenting with ST-elevation in the initial electrocardiogram underwent acute coronary arteriography (CAG) and percutaneous coronary intervention (PCI) when feasible. If cardiogenic shock was present, an IABP was placed, according to the recommended guidelines at that time. ${ }^{2}$ When factors other than cardiac etiology of the arrest were suspected to be present at admission, a cerebral computed tomography scan was performed to exclude intracranial hemorrhage. Once this was confirmed, the patient was transferred to another center for neurosurgical treatment when indicated, and these patients were excluded from the study.

\section{Cooling methods}

Active cooling was initiated at the place of cardiac arrest if possible, else it was initiated immediately after admission to the emergency room (or the ICU in IHCA patients) with ice bags on the torso and infusion of $30 \mathrm{~mL} / \mathrm{kg}$ of $4^{\circ} \mathrm{C}$ isotonic saline solution. Surface cooling was continued in the ICU using a surface cooling system (Arctic Sun ${ }^{\circledR}$; Medivance Corp, Louisville, Co., or Allon $2001^{\circledR}$; MTRE Advanced Technologies Ltd, Or-Akiva Industrial Park, Israel). Patients were sedated with propofol and remifentanil to a Sedation Agitation Scale (SAS) 1. Muscle shivering was treated with increased sedation and if necessary with cisatracurium $(0.05 \mathrm{mg} / \mathrm{kg}$ IV). Seizures and myoclonus during TTM were treated according to local guidelines. Continuous infusion of vasoactive drugs (norepinephrine, dopamine, epinephrine, or dobutamine) was administered to maintain mean arterial blood pressure $>60 \mathrm{mmHg}$.

When a target temperature of $33^{\circ} \mathrm{C}$ was achieved, attempts were made to maintain it for $24 \mathrm{~h}$, followed by rewarming at a maximum rate of $0.5^{\circ} \mathrm{C} / \mathrm{h}$ according to the guidelines. When patients were normothermic, sedation was discontinued. Recommendations from the American Academy of Neurology were followed and neurologic prognostication was performed on patients who remained comatose $>72 \mathrm{~h}$ after cardiac arrest or $24 \mathrm{~h}$ after normothermia and at least $12 \mathrm{~h}$ after sedation was discontinued.

\section{Data collection}

Four investigators collected data from the ICU database, medical charts from the department of cardiology, and the emergency medical service (EMS). Data included age, sex, body mass index (BMI), date of admission and discharge from the ICU and the hospital, presence of prehospital comorbidities (diabetes, hypertension, hypercholesterolemia, and ischemic heart disease), initial rhythm, site of arrest 
(in- or out-of-hospital), CPR by bystander, time from arrest to ROSC, presumed etiology of cardiac arrest (ST-elevation myocardial infarction [STEMI], non-STEMI, primary arrhythmia, and noncardiac cause), whether acute CAG, primary PCI, placement of an IABP, or placement of a temporary pacemaker was performed. Additionally, we collected data on the use of vasoactive drugs as continuous infusion in the ICU (epinephrine, norepinephrine, dobutamine, dopamine, milrinone, or levosimendan) and duration of TTM in hours. Neurological status at discharge from the ICU and hospital was retrieved from patient files and ICU database. The status details were categorized using the Pittsburgh cerebral performance categories (CPC) scale. ${ }^{13,14} \mathrm{~A}$ good neurologic outcome was defined as $\mathrm{CPC}=1$ or 2 (corresponding to no or minor incapacity). A poor neurologic outcome was defined as $\mathrm{CPC}=3$ (severe disability, dependent), $\mathrm{CPC}=4$ (coma or vegetative state), or $\mathrm{CPC}=5$ (death).

The study was approved by the Danish Patient Safety Authority and the Danish Data Protection Agency. Due to the retrospective nature of the study and high mortality in the study population, written informed consent could not be obtained from all patients and was therefore waived by the Danish Patient Safety Authority.

\section{Statistical methods}

This study was divided into two parts: 1) survival to hospital discharge comparing OHCA and IHCA and 2) long-term survival after hospital discharge comparing OHCA and IHCA.

The first part compared short-term survival during initial admission after OHCA and IHCA by using logistic regression and identified factors associated with survival. In a subanalysis of short-term survival, patients with known initial rhythm were classified into four subgroups: OHCA and IHCA with shockable initial rhythm and OHCA and IHCA with nonshockable initial rhythm.

The final part compared long-term survival after OHCA and IHCA using Cox logistic regression and identified prognostic factors for survival. Observation time was calculated from date of discharge to date of death, lost to follow-up, emigration, or October 1, 2011, whichever came first.

Differences in baseline characteristics, survival, and neurologic outcome between OHCA and IHCA groups were estimated using chi-square test and Kruskal-Wallis test as appropriate. All estimates $<0.05$ were considered statistically significant.

Kaplan-Meier curves were used to illustrate cumulative long-term survival. Multivariate logistic regression analysis and Cox regression analysis were performed to determine the association of clinical variables with survival to hospital discharge and with long-term survival, respectively. Factors associated with long-term survival were calculated as the reciprocal of the hazard ratio (HR). As the time from collapse to ROSC was not found to be a linear variable, it was entered as a categorical variable in the model. For the purpose of the analysis, the median time from collapse to ROSC of the total cohort was selected and dichotomized as $<10 \mathrm{~min}$ or $=10 \mathrm{~min}$ or $>10 \mathrm{~min}$. Age was divided into 10 -year categories, and a significant difference was found between $>60$ and $<60$ years. The following covariables were used to identify the predictors of survival, in both Parts 1 and 2: site of cardiac arrest (OHCA vs IHCA), gender (male vs female), age ( $\leq 60$ vs $>60$ years), CPR by bystander (yes vs no), time to ROSC ( $\leq 10$ vs $>10 \mathrm{~min}$ ), initial rhythm (shockable vs non-shockable vs unknown), and etiology of cardiac arrest (STEMI vs etiology other than STEMI). All statistical analyses were carried out in SPSS version 11.5 software (SPSS, Chicago, IL, USA).

\section{Results \\ Patient characteristics}

A total of 282 consecutive patients (233 with OHCA and 49 with IHCA) were included in the study. Table 1 shows the baseline demographics of OHCA and IHCA patients with comparison between groups. The IHCA patients presented more often with asystole and less with VF, received CPR by bystander in all cases, and had shorter median time from arrest to ROSC. Other differences were the more frequent performance of acute $\mathrm{CAG}$ in the OHCA group and the more frequent placement of a temporary pacemaker in the IHCA group.

TTM was interrupted before $12 \mathrm{~h}$ in $3 \%$ of OHCA $(7 / 233)$ and $2 \%$ of IHCA patients $(1 / 49)$, due to refractory circulatory shock, lactate acidosis, or intestinal ischemia. In the rest of the patients, duration of TTM was maintained between 12 and $24 \mathrm{~h}$ as international guidelines dictate.

\section{Outcomes}

In Part 1 (short-term survival), there was no difference in survival to hospital discharge between the groups: 54\% (125/233) for OHCA and 53\% (26/49) for IHCA (adjusted OR [95\% CI], 0.98 [0.43-2.24]) (Table 2). Factors associated with survival to hospital discharge were age $\leq 60$ years (adjusted OR [95\% CI], 3.33 [1.86-5.95]), CPR by bystander (adjusted OR [95\% CI], 2.42 [1.28-4.55]), time to ROSC 
Table I Baseline characteristics of OHCA and IHCA patients treated with targeted temperature management

\begin{tabular}{|c|c|c|c|}
\hline Characteristics & $\begin{array}{l}\text { OHCA } \\
n=233(83 \%)\end{array}$ & $\begin{array}{l}\text { IHCA } \\
n=49(17 \%)\end{array}$ & $P$-value \\
\hline Male, n (\%) & $182(78)$ & $37(76)$ & 0.691 \\
\hline Age, years, median (IQR) & $64(55-73)$ & $64(57-74)$ & 0.761 \\
\hline BMI, median (IQR) & $25(23-28)$ & 26 (24-29) & 0.135 \\
\hline \multicolumn{4}{|l|}{ Initial rhythm, n (\%) } \\
\hline VF & $168(72)$ & $19(39)$ & $<0.001$ \\
\hline$p \vee T$ & $13(6)$ & $2(4)$ & \\
\hline Asystole & $23(10)$ & $16(33)$ & \\
\hline PEA & $22(9)$ & $7(14)$ & \\
\hline Unknown & $7(3)$ & $5(10)$ & \\
\hline \multicolumn{4}{|l|}{$\begin{array}{l}\text { Pre-arrest cardiovascular } \\
\text { comorbidity, n (\%) }\end{array}$} \\
\hline Diabetes & $29(12)$ & $5(10)$ & 0.661 \\
\hline Hypertension & $70(30)$ & $21(43)$ & 0.081 \\
\hline Hypercholesterolemia & $32(14)$ & $7(14)$ & 0.919 \\
\hline Ischemic heart disease & $5 I(22)$ & II (22) & 0.931 \\
\hline CPR by bystander, n (\%) & $145(62)$ & $49(100)$ & $<0.001$ \\
\hline $\begin{array}{l}\text { Time to ROSC ( } \mathrm{min}) \text {, } \\
\text { median (IQR) }\end{array}$ & $15(10-23)$ & $10(6-15)$ & $<0.001$ \\
\hline \multicolumn{4}{|l|}{ Etiology of cardiac arrest } \\
\hline STEMI, n (\%) & $122(52)$ & $17(35)$ & 0.054 \\
\hline NSTEMI, n (\%) & $24(10)$ & $5(10)$ & \\
\hline $\begin{array}{l}\text { Primary arrhythmia, } \\
\mathrm{n}(\%)\end{array}$ & $44(19)$ & $10(20)$ & \\
\hline Noncardiac, n (\%) & $43(18)$ & $17(35)$ & \\
\hline Acute CAG, n (\%) & $156(67)$ & $25(5 \mathrm{I})$ & 0.034 \\
\hline Primary PCI, n (\%) & $102(44)$ & $18(37)$ & 0.516 \\
\hline IABP, n (\%) & $21(9)$ & $7(14)$ & 0.262 \\
\hline $\begin{array}{l}\text { Temporary pacemaker, } \\
\text { n (\%) }\end{array}$ & $34(15)$ & $13(27)$ & 0.042 \\
\hline \multicolumn{4}{|l|}{ Vasoactive drugs, n (\%) } \\
\hline Epinephrine* & $35(15)$ & $13(27)$ & 0.051 \\
\hline Other vasoactive drugs & $182(78)$ & $32(65)$ & 0.057 \\
\hline No vasoactive drugs & $16(7)$ & $4(8)$ & 0.748 \\
\hline \multicolumn{4}{|l|}{$\begin{array}{l}\text { Length of admission, } \\
\text { median days (IQR) }\end{array}$} \\
\hline At ICU & $4(3-7)$ & $4(2-8)$ & 0.534 \\
\hline In total & $8(5-12)$ & $8(3-12)$ & 0.440 \\
\hline $\begin{array}{l}\text { Survival to hospital } \\
\text { discharge, } n(\%)\end{array}$ & $125(54)$ & $26(53)$ & 0.940 \\
\hline $\begin{array}{l}\text { CPC I-2 at hospital } \\
\text { discharge }\end{array}$ & $107(86)$ & $24(92)$ & 0.829 \\
\hline
\end{tabular}

Note: *Epinephrine given along with other vasoactive drugs.

Abbreviations: BMI, body mass index; CAG, coronary arteriography; CPC, cerebral performance categories; CPR, cardiopulmonary resuscitation; IABP, intraaortic balloon pump; ICU, intensive care unit; IHCA, in-hospital cardiac arrest; $\mathrm{IQR}$, interquartile range; OHCA, out-of-hospital cardiac arrest; $\mathrm{PCl}$, percutaneous coronary intervention; PEA, pulseless electrical activity; $p V T$, pulseless ventricular tachycardia; ROSC, return of spontaneous circulation; STEMI, ST segment elevation myocardial infarction; NSTEMI, non-segment elevation myocardial infarction; VF, ventricular fibrillation.

$\leq 10$ min (adjusted OR [95\% CI], 3.63 [1.94-6.76]), and shockable rhythm at presentation (adjusted OR [95\% CI], 6.14 [2.88-13.09]) (Table 2). In the subanalysis including only those with a known initial rhythm (226 OHCA patients
Table 2 Logistic regression analysis of variables associated with survival to hospital discharge in OHCA and IHCA patients treated with targeted temperature management

\begin{tabular}{|c|c|c|c|}
\hline Characteristics & $\begin{array}{l}\text { Survivors } \\
N=|5| \text { (\%) }\end{array}$ & $\begin{array}{l}\text { Unadjusted OR } \\
(95 \% \mathrm{Cl})\end{array}$ & $\begin{array}{l}\text { Adjusted OR** } \\
(95 \% \mathrm{Cl})\end{array}$ \\
\hline \multicolumn{4}{|l|}{ Cardiac arrest site } \\
\hline IHCA & $26(17)$ & $0.98(0.53-1.8 \mathrm{I})$ & $0.98(0.43-2.24)$ \\
\hline OHCA & $125(83)$ & I (ref) & I (ref) \\
\hline \multicolumn{4}{|l|}{ Gender } \\
\hline Male & I23 (8I) & $1.60(0.91-2.82)$ & $1.24(0.64-2.37)$ \\
\hline Female & $28(19)$ & I (ref) & I (ref) \\
\hline \multicolumn{4}{|l|}{ Age } \\
\hline$\leq 60$ years & $73(48)$ & $3.20(1.91-5.35)$ & $3.33(1.86-5.95)$ \\
\hline$>60$ years & $78(52)$ & I (ref) & I (ref) \\
\hline \multicolumn{4}{|l|}{ CPR by bystander } \\
\hline $\begin{array}{l}\text { CPR by } \\
\text { bystander }\end{array}$ & III (74) & $1.97(1.15-3.38)$ & $2.42(1.28-4.55)$ \\
\hline No bystander & $40(26)$ & I (ref) & I (ref) \\
\hline \multicolumn{4}{|l|}{ Time to ROSC } \\
\hline $\mathrm{ROSC} \leq 10 \mathrm{~min}$ & $66(44)$ & $2.58(1.53-4.36)$ & $3.63(1.94-6.76)$ \\
\hline $\mathrm{ROSC}>10 \mathrm{~min}$ & $85(56)$ & I (ref) & I (ref) \\
\hline \multicolumn{4}{|l|}{ Initial rhythm } \\
\hline Shockable & $129(85)$ & $5.59(3.0 \mathrm{I}-10.40)$ & $6.14(2.88-13.09)$ \\
\hline Non-shockable & $16(1 \mathrm{I})$ & I (ref) & I (ref) \\
\hline Unknown*** & $6(4)$ & $0.87(0.27-2.78)$ & $1.98(0.49-7.98)$ \\
\hline \multicolumn{4}{|l|}{$\begin{array}{l}\text { Etiology of cardiac } \\
\text { arrest }\end{array}$} \\
\hline STEMI & $86(57)$ & $1.97(1.22-3.18)$ & $1.28(0.73-2.26)$ \\
\hline $\begin{array}{l}\text { Other } \\
\text { etiology**** }\end{array}$ & $65(43)$ & I (ref) & I (ref) \\
\hline
\end{tabular}

Notes: **Adjusted for site of cardiac arrest (IHCA vs OHCA), gender (male vs female), age ( $\leq 60$ years vs $>60$ years), CPR by bystander (yes vs no), time to ROSC ( $\leq 10$ vs $>10 \mathrm{~min}$ ), initial rhythm (shockable vs non-shockable vs unknown), and etiology of cardiac arrest (STEMI vs etiology other than STEMI). *** Unknown initial rhythm. ****Other etiology: non-STEMI, primary arrhythmia, and noncardiac causes. Abbreviations: $\mathrm{Cl}$, confidence interval; $\mathrm{CPR}$, cardiopulmonary resuscitation; IHCA, in-hospital cardiac arrest; OHCA, out-of-hospital cardiac arrest; OR, odds ratio; ref, reference; ROSC, return of spontaneous circulation; STEMI, ST segment elevation myocardial infarction.

and 44 IHCA patients), the crude ORs for survival to hospital discharge for shockable OHCA and IHCA were 7.90 (95\% CI, 3.50-17.90) and 11.60 (95\% CI, 3.42-39.03), respectively, compared with non-shockable OHCA (reference group), whereas the crude OR for non-shockable IHCA was 2.50 (95\% CI, 0.78-7.80).

Part 2 (long-term survival) included a total of $125 \mathrm{OHCA}$ and 26 IHCA patients who survived to hospital discharge with a median of 5.0 years (interquartile range [IQR], 3.7-6.3) and 5.8 years (IQR, 4.2-8.6) of observation, respectively. The two groups consisted mainly of male patients ( $81 \%$ vs $82 \%$ ) with a median age of 61 years (Table 3 ). There was no difference in time to ROSC between the groups. The main differences were a higher number of IHCA patients with non-shockable rhythm at presentation (IHCA, 30\% vs OHCA, 6\%), a higher 
Table 3 Baseline characteristics of OHCA and IHCA patients treated with targeted temperature management who survived to hospital discharge

\begin{tabular}{|c|c|c|c|}
\hline Characteristics & $\begin{array}{l}\text { OHCA } \\
n=125\end{array}$ & $\begin{array}{l}\text { IHCA } \\
n=26\end{array}$ & $P$-value \\
\hline Male, n (\%) & $102(82)$ & $2 I(8 I)$ & 0.921 \\
\hline Age, years, median (IQR) & 61 (53-69) & 61 (54-73) & 0.536 \\
\hline \multicolumn{4}{|l|}{ Initial rhythm, n (\%) } \\
\hline VF & $105(84)$ & $14(54)$ & 0.001 \\
\hline pVT & $9(7)$ & $\mathrm{I}(4)$ & \\
\hline Asystole & $4(3)$ & $4(15)$ & \\
\hline PEA & $4(3)$ & $4(15)$ & \\
\hline Unknown & $3(2)$ & $2(8)$ & \\
\hline \multicolumn{4}{|l|}{ Pre-arrest comorbidity, n (\%) } \\
\hline Diabetes & $9(7)$ & $0(0)$ & 0.158 \\
\hline Hypertension & $38(30)$ & II (42) & 0.238 \\
\hline Hypercholesterolemia & $13(10)$ & $3(12)$ & 0.864 \\
\hline Ischemic heart disease & $24(19)$ & $3(12)$ & 0.354 \\
\hline CPR by bystander, n (\%) & $87(70)$ & $26(100)$ & 0.001 \\
\hline $\begin{array}{l}\text { Time to ROSC ( } \mathrm{min}) \text {, median } \\
\text { (IQR) }\end{array}$ & $14(8-20)$ & $10.5(6-17)$ & 0.186 \\
\hline \multicolumn{4}{|l|}{ Etiology of cardiac arrest } \\
\hline STEMI, n (\%) & $72(58)$ & $14(54)$ & 0.725 \\
\hline NSTEMI, n (\%) & $14(I I)$ & $2(8)$ & \\
\hline Primary arrhythmia, n (\%) & $24(19)$ & $7(27)$ & \\
\hline Noncardiac, n (\%) & $15(12)$ & $3(12)$ & \\
\hline Acute CAG, n (\%) & $90(72)$ & $18(69)$ & 0.776 \\
\hline Primary PCl, n (\%) & $61(49)$ & $13(50)$ & 0.911 \\
\hline \multicolumn{4}{|l|}{ Vasoactive drugs, n (\%) } \\
\hline Epinephrine* & $8(6)$ & $5(19)$ & 0.034 \\
\hline Other vasoactive drugs & $105(84)$ & $19(73)$ & 0.186 \\
\hline No vasoactive drugs & $12(10)$ & $2(8)$ & 0.760 \\
\hline IABP, n (\%) & II (9) & $4(15)$ & 0.307 \\
\hline Temporary pacemaker, n (\%) & $14(I I)$ & $7(27)$ & 0.035 \\
\hline $\begin{array}{l}\text { Length of hospital stay, } \\
\text { median days (IQR) }\end{array}$ & $11(6-16)$ & $9(5-15)$ & 0.189 \\
\hline CPC I-2 at hospital discharge & $106(85)$ & $24(92)$ & 0.642 \\
\hline
\end{tabular}

Note: *Epinephrine given along with other vasoactive drugs

Abbreviations: CAG, coronary arteriography; CPC, cerebral performance categories; CPR, cardiopulmonary resuscitation; IABP, intra-aortic balloon pump; IHCA, in-hospital cardiac arrest; IQR, interquartile range; OHCA, out-of-hospital cardiac arrest; $\mathrm{PCl}$, percutaneous coronary intervention; PEA, pulseless electrical activity; pVT, pulseless ventricular tachycardia; ROSC, return of spontaneous circulation; STEMI, ST segment elevation myocardial infarction; NSTEMI, nonsegment elevation myocardial infarction; VF, ventricular fibrillation.

rate of CPR by bystander (IHCA, 100\% vs OHCA, 70\%), and a higher rate of placement of a temporary pacemaker in the IHCA group (IHCA, 27\% vs OHCA, 11\%). About $92 \%$ of OHCA and $92 \%$ of IHCA patients were alive after 1 year, and $83 \%$ of OHCA and $77 \%$ of IHCA were alive at the end of observation. Long-term survival did not differ significantly (Figure 1) (adjusted HR [95\% CI], 1.51 [0.59-3.91]).

Age $\leq 60$ years (adjusted HR [95\% CI], 2.73 [1.36-5.52]) was the only independent factor associated with long-term survival (Table 4). Good neurologic outcome (CPC 1 or 2) prior to hospital discharge among survivors was seen in $86 \%$
$(107 / 125)$ of OHCA and $92 \%(24 / 26)$ of IHCA patients (Table 1).

\section{Discussion}

The present study shows no difference in short- and longterm survival and no difference in neurologic outcome prior to hospital discharge between consecutive OHCA and IHCA patients treated with TTM despite increased rate of asystole as initial rhythm in the IHCA group.

Only one study has previously compared IHCA with OHCA, and their findings are in concordance with this study as they found no difference in survival. ${ }^{15}$ Unfortunately, data on TTM were not available in that study. In general, IHCA has not received the same level of focused research as OHCA, and there are no controlled randomized studies regarding the use of TTM after IHCA. Results from cohort studies show that TTM did not improve the outcomes in this population, although the results might have been influenced by the poor implementation of TTM and the low achievement of target temperature after IHCA. ${ }^{16-18}$

In terms of age, gender, and preexisting comorbidities, the two populations in our study were comparable. One of the main differences between the two populations is the larger fraction of patients with asystole or pulseless electrical activity as initial rhythm in the IHCA group. The proportions of shockable and non-shockable rhythms in IHCA patients vary substantially in other reports due to differences in patient populations and settings. ${ }^{8,11,15,16,19,20}$ Still, the proportions of $\mathrm{VF}$ and asystole in IHCA patients are comparable to that reported in a recent study conducted in a setting similar to the present analysis. ${ }^{21}$ Time to ROSC was short not only for IHCA patients but also for OHCA patients due to the highly effective EMS covering the Copenhagen area. ${ }^{22}$

Even though IHCA patients are typically described as being in poorer condition with a significantly higher degree of comorbidity than OHCA patients and therefore at a higher risk of death per se, no significant differences were found regarding pre-arrest cardiovascular comorbidity between the groups. ${ }^{23,24}$ Not surprisingly, the strongest predictor of survival in this study was the presence of a shockable initial rhythm, a prognostic factor that is thoroughly demonstrated in several other studies. ${ }^{22,25-27} \mathrm{~A}$ subanalysis in our study also demonstrated that the prognosis of both shockable and nonshockable initial rhythm in IHCA patients was better than that for OHCA patients. This finding was not surprising, since no difference was found in pre-arrest comorbidity and the IHCA patients had a higher frequency of CPR by bystander and shorter time to ROSC, which were also identified as 


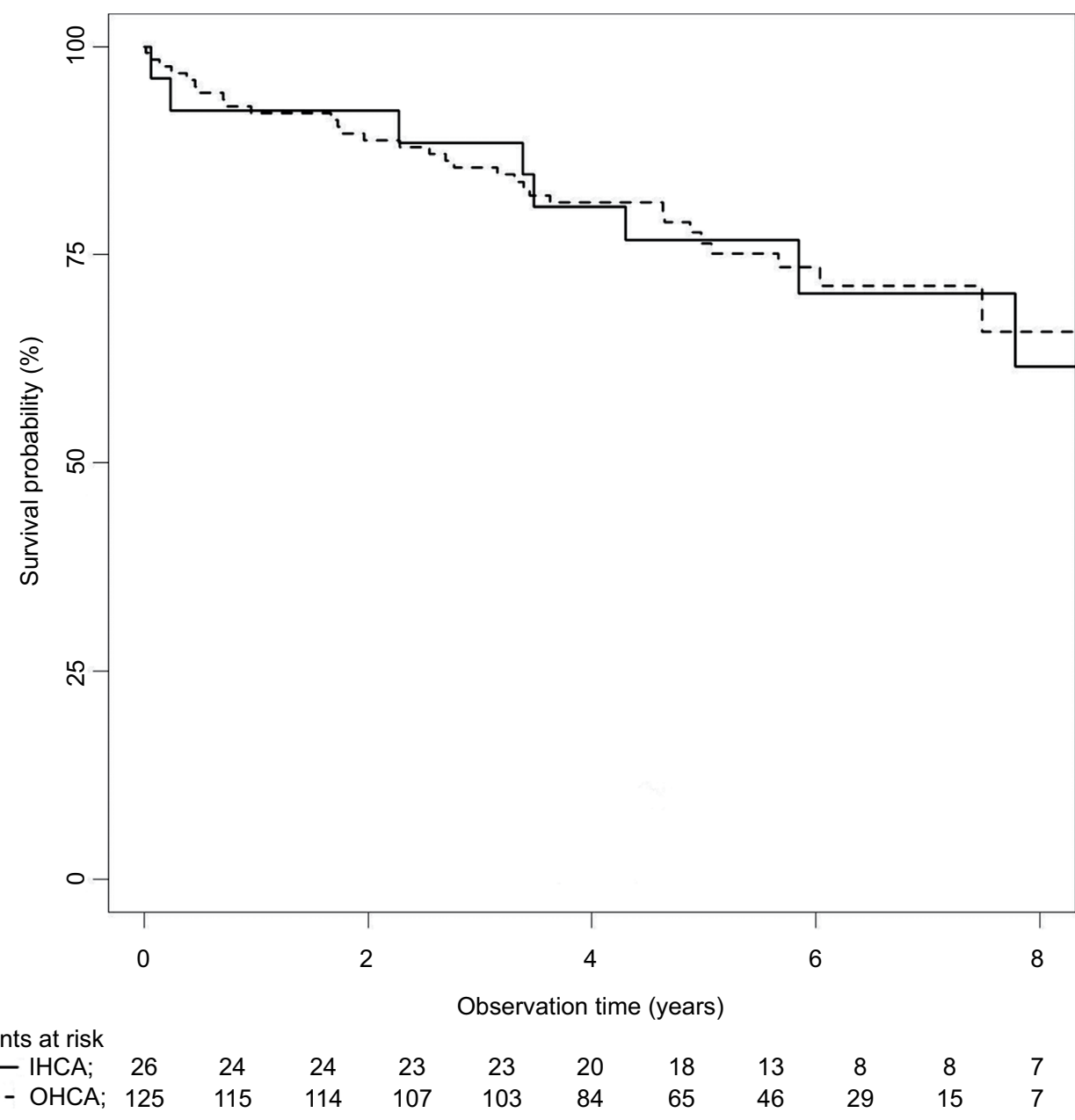

Figure I Kaplan-Meier curves illustrating cumulative long-term survival in OHCA and IHCA patients treated with targeted temperature management. Abbreviations: IHCA, in-hospital cardiac arrest; OHCA, out-of-hospital cardiac arrest.

factors strongly associated with survival. Besides this, it is presumed that cardiac arrest is recognized earlier, that time to initiation of advanced life support is shorter, that potentially reversible causes are treated more swiftly, and that the quality of acute resuscitation, ventilation, and chest compressions is higher in the in-hospital setting, thereby contributing to increased survival. Furthermore, the study was conducted at a hospital with invasive cardiological expertise available day and night, thereby shortening the time to acute CAG, primary percutaneous intervention, insertion of temporary pacemaker, and IABP among IHCA patients, leading to improved odds for IHCA patients.

The long-term survival in the two populations did not differ, and age was identified as the sole prognostic factor for survival. Thus, in this study survival to hospital discharge after cardiac arrest eliminated any differences in prognosis related to initial rhythm, CPR by bystander, and time to ROSC.
The main advantage of this study is that it includes consecutive cardiac arrest patients with complete follow-up on survival. Besides this, the study achieved target temperature in all patients, and the duration of treatment was between 12 and $24 \mathrm{~h}$, as dictated by the guidelines, in $98 \%$ and $97 \%$ of the patients, thus making the comparison of the two groups more reliable. Finally, this is the only study that has compared consecutive OHCA and IHCA patients and described their long-term survival.

The main limitation of the present study is the limited number of IHCA patients, which decreased the strength of the results and did not allow for propensity-matched analysis. Furthermore, the present study did not have detailed information on noncardiac causes of cardiac arrest which could have explained the lack of difference in survival between the two populations. Another limitation is that in order to be treated with TTM, the IHCA patients must fulfill strict inclusion criteria, thereby introducing a selection bias making them a 
Table 4 Univariate and multivariate Cox regression analysis of factors associated with long-term survival after hospital discharge in OHCA and IHCA patients treated with targeted temperature management

\begin{tabular}{|c|c|c|c|}
\hline Characteristics & $\begin{array}{l}\text { Survivors } \\
N=151 \text { (\%) }\end{array}$ & $\begin{array}{l}\text { Unadjusted } \\
\text { HR }(95 \% \mathrm{Cl})\end{array}$ & $\begin{array}{l}\text { Adjusted HR** } \\
(95 \% \mathrm{Cl})\end{array}$ \\
\hline \multicolumn{4}{|l|}{ Cardiac arrest site } \\
\hline $\mathrm{IHCA}$ & $26(17)$ & $0.8 \mathrm{I}(0.37-1.76)$ & I.5I (0.59-3.9I) \\
\hline OHCA & $125(83)$ & I (ref) & I (ref) \\
\hline \multicolumn{4}{|l|}{ Gender } \\
\hline Male & $123(8 \mathrm{I})$ & $\mathrm{I} .33(0.6 \mathrm{I}-2.90)$ & $1.24(0.5-2.77)$ \\
\hline Female & $28(19)$ & I (ref) & I (ref) \\
\hline \multicolumn{4}{|l|}{ Age } \\
\hline$\leq 60$ years & $73(48)$ & $2.42(1.22-4.76)$ & $2.73(1.36-5.52)$ \\
\hline$>60$ years & $78(52)$ & I (ref) & I (ref) \\
\hline \multicolumn{4}{|l|}{ CPR by bystander } \\
\hline $\begin{array}{l}\text { CPR by } \\
\text { bystander }\end{array}$ & III (74) & $1.00(0.46-2.16)$ & $0.92(0.4 I-2.06)$ \\
\hline No bystander & $40(26)$ & I (ref) & I (ref) \\
\hline \multicolumn{4}{|l|}{ Time to ROSC } \\
\hline ROSC $\leq 10$ min & $66(44)$ & $0.83(0.44-\mathrm{I} .56)$ & $1.06(0.54-2.10)$ \\
\hline ROSC $>10 \mathrm{~min}$ & $85(56)$ & I (ref) & I (ref) \\
\hline \multicolumn{4}{|l|}{ Initial rhythm } \\
\hline Shockable & $129(85)$ & $1.85(0.72-4.72)$ & I.89 (0.68-5.24) \\
\hline Non-shockable & $16(11)$ & I (ref) & I (ref) \\
\hline Unknown*** & $6(4)$ & $0.61(0.15-2.44)$ & $0.42(0.10-1.75)$ \\
\hline \multicolumn{4}{|l|}{$\begin{array}{l}\text { Etiology of cardiac } \\
\text { arrest }\end{array}$} \\
\hline STEMI & $86(57)$ & $1.66(0.88-3.12)$ & $1.25(0.63-2.45)$ \\
\hline $\begin{array}{l}\text { Other } \\
\text { etiology } * * * *\end{array}$ & $65(43)$ & I (ref) & I (ref) \\
\hline
\end{tabular}

Notes: **Adjusted for site of cardiac arrest (IHCA vs OHCA), gender (male vs female), age ( $\leq 60$ years vs $>60$ years), CPR by bystander (yes vs no), time to ROSC ( $\leq 10$ vs $>10 \mathrm{~min}$ ), initial rhythm (shockable vs non-shockable vs unknown), and etiology of cardiac arrest (STEMI vs etiology other than STEMI). ****Unknown initial rhythm. ****Other etiology: non-STEMI, primary arrhythmia, and noncardiac causes. Abbreviations: $\mathrm{Cl}$, confidence interval; $\mathrm{CPR}$, cardiopulmonary resuscitation; HR, hazard ratio; IHCA, in-hospital cardiac arrest; OHCA, out-of-hospital cardiac arrest; ref, reference; ROSC, return of spontaneous circulation; STEMI, ST segment elevation myocardial infarction.

highly selected group with improved prognosis. As a consequence, the results cannot be transferred to IHCA patients in general. In addition, data on long-term follow-up of neurologic function were not collected, and therefore, inferences on the long-term neurologic outcome cannot be drawn.

\section{Conclusion}

This study shows no difference in survival and neurologic outcome at hospital discharge between consecutive OHCA and IHCA patients treated with TTM at a Danish tertiary university heart center despite higher frequency of asystole in the IHCA group. Even though asystole is usually associated with poor outcome, it may have been counteracted by a high rate of bystander CPR and short time to ROSC.

\section{Disclosure}

The first and the last author are related by marriage. The authors report no conflicts of interest in this work.

\section{References}

1. Wissenberg M, Lippert FK, Folke F, et al. Association of national initiatives to improve cardiac arrest management with rates of bystander intervention and patient survival after out-of-hospital cardiac arrest. JAMA. 2013;310:1377-1384.

2. Nolan JP, Soar J, Zideman DA, et al. European Resuscitation Council Guidelines for Resuscitation 2010 Section 1. Executive summary. Resuscitation. 2010;81:1219-1276.

3. Negovsky VA. The second step in resuscitation the treatment of the "post-resuscitation disease." Resuscitation. 1972;1(1):1-7.

4. Bernard SA, Gray TW, Buist MD, Jones BM, Silvester W, Gutteridge $\mathrm{G}$, Smith K. Treatment of comatose survivors of out-of-hospital cardiac arrest with induced hypothermia. N Engl J Med. 2002;346:557-563.

5. Hypothermia after Cardiac Arrest Study Group. mild therapeutic hypothermia to improve the neurologic outcome after cardiac arrest. $N E n g l$ J Med. 2002;346:549-556.

6. Nielsen N, Wetterslev J, Cronberg T, et al. Targeted temperature management at 33 degrees $\mathrm{C}$ versus 36 degrees $\mathrm{C}$ after cardiac arrest. $N$ Engl J Med. 2013;369:2197-2206.

7. Callaway CW, Donnino MW, Fink EL, et al. Part 8: post-cardiac arrest care: 2015 American Heart Association Guidelines Update for Cardiopulmonary Resuscitation and Emergency Cardiovascular Care. Circulation. 2015;132:S465-S482.

8. Oddo M, Schaller MD, Feihl F, Ribordy V, Liaudet L. From evidence to clinical practice: effective implementation of therapeutic hypothermia to improve patient outcome after cardiac arrest. Crit Care Med. 2006;34:1865-1873

9. Lundbye JB, Rai M, Ramu B, et al. Therapeutic hypothermia is associated with improved neurologic outcome and survival in cardiac arrest survivors of non-shockable rhythms. Resuscitation. 2012;83:202-207.

10. Holzer M, Mullner M, Sterz F, et al. Efficacy and safety of endovascular cooling after cardiac arrest: cohort study and Bayesian approach. Stroke. 2006;37:1792-1797.

11. Gaieski DF, Band RA, Abella BS, et al. Early goal-directed hemodynamic optimization combined with therapeutic hypothermia in comatose survivors of out-of-hospital cardiac arrest. Resuscitation. 2009;80:418-424.

12. Nolan JP, Morley PT, Vanden Hoek TL, et al. Therapeutic hypothermia after cardiac arrest: an advisory statement by the advanced life support task force of the International Liaison Committee on Resuscitation. Circulation. 2003;108:118-121.

13. Brain Resuscitation Clinical Trial II Study Group. A randomized clinical study of a calcium-entry blocker (lidoflazine) in the treatment of comatose survivors of cardiac arrest. N Engl J Med. 1991;324:1225-1231.

14. Jacobs I, Nadkarni V, Bahr J, et al. Cardiac arrest and cardiopulmonary resuscitation outcome reports: update and simplification of the Utstein templates for resuscitation registries: a statement for healthcare professionals from a task force of the International Liaison Committee on Resuscitation (American Heart Association, European Resuscitation Council, Australian Resuscitation Council, New Zealand Resuscitation Council, Heart and Stroke Foundation of Canada, InterAmerican Heart Foundation, Resuscitation Councils of Southern Africa). Circulation. 2004;110:3385-3397.

15. Buanes EA, Heltne JK: Comparison of in-hospital and out-of-hospital cardiac arrest outcomes in a Scandinavian community. Acta Anaesthesiol Scand. 2014;58:316-322.

16. Mikkelsen ME, Christie JD, Abella BS, et al. Use of therapeutic hypothermia after in-hospital cardiac arrest. Crit Care Med. 2013;41: $1385-1395$. 
17. Arrich J. Clinical application of mild therapeutic hypothermia after cardiac arrest. Crit Care Med. 2007;35:1041-1047.

18. Nichol G, Huszti E, Kim F, et al. Does induction of hypothermia improve outcomes after in-hospital cardiac arrest? Resuscitation. 2013;84: 620-625.

19. Nolan JP, Soar J, Smith GB, et al. Incidence and outcome of in-hospital cardiac arrest in the United Kingdom National Cardiac Arrest Audit. Resuscitation. 2014;85:987-992.

20. Meaney PA, Nadkarni VM, Kern KB, Indik JH, Halperin HR, Berg RA. Rhythms and outcomes of adult in-hospital cardiac arrest. Crit Care Med. 2010;38:101-108.

21. Dankiewicz J, Schmidbauer S, Nielsen N, et al. Safety, feasibility, and outcomes of induced hypothermia therapy following in-hospital cardiac arrest-evaluation of a large prospective registry. Crit Care Med. 2014;42(12):2537-2545.

22. Soholm H, Wachtell K, Nielsen SL, et al. Tertiary centres have improved survival compared to other hospitals in the Copenhagen area after outof-hospital cardiac arrest. Resuscitation. 2013;84:162-167.
23. Skrifvars MB, Castren M, Nurmi J, Thoren AB, Aune S, Herlitz J. Do patient characteristics or factors at resuscitation influence long-term outcome in patients surviving to be discharged following in-hospital cardiac arrest? J Intern Med. 2007;262:488-495.

24. Sandroni C, Nolan J, Cavallaro F, Antonelli M. In-hospital cardiac arrest: incidence, prognosis and possible measures to improve survival. Intensive Care Med. 2007;33:237-245.

25. Aguila A, Funderburk M, Guler A, et al. Clinical predictors of survival in patients treated with therapeutic hypothermia following cardiac arrest. Resuscitation. 2010;81:1621-1626.

26. Herlitz J, Bang A, Gunnarsson J, Engdahl J, Karlson BW, Lindqvist J, Waagstein L. Factors associated with survival to hospital discharge among patients hospitalised alive after out of hospital cardiac arrest: change in outcome over 20 years in the community of Goteborg, Sweden. Heart. 2003;89:25-30.

27. Meaney PA, Nadkarni VM, Kern KB, Indik JH, Halperin HR, Berg RA. Rhythms and outcomes of adult in-hospital cardiac arrest. Crit Care Med. 2010;38:101-108.
Clinical Epidemiology

\section{Publish your work in this journal}

Clinical Epidemiology is an international, peer-reviewed, open access, online journal focusing on disease and drug epidemiology, identification of risk factors and screening procedures to develop optimal preventative initiatives and programs. Specific topics include: diagnosis, prognosis, treatment, screening, prevention, risk factor modification,

Submit your manuscript here: https://www.dovepress.com/clinical-epidemiology-journa
Dovepress

systematic reviews, risk and safety of medical interventions, epidemiology and biostatistical methods, and evaluation of guidelines, translational medicine, health policies and economic evaluations. The manuscript management system is completely online and includes a very quick and fair peer-review system, which is all easy to use. 